\title{
BMJ
}

\section{Psychosocial outcomes of three triage methods for the management of borderline abnormal cervical smears: an open randomised trial}

\begin{abstract}
Kirsten J McCaffery, senior research fellow, ${ }^{1}$ Les Irwig, professor of epidemiology, ${ }^{1}$ Robin Turner, research fellow, biostatistics, ${ }^{1}$ Siew Foong Chan, statistician, ${ }^{1}$ Petra Macaskill, associate professor in biostatistics , Mary Lewicka, research assistant, Judith Clarke, research assistant, ${ }^{1}$ Edith Weisberg, director research ,2 Alex Barratt, associate professor in epidemiology ${ }^{1}$
\end{abstract}

${ }^{1}$ Screening and Test Evaluation Program, School of Public Health, University of Sydney, NSW 2006, Australia

${ }^{2}$ Sydney Centre for Reproductive Health Research, Family Planning NSW, Sydney, Australia

Correspondence to: Kirsten McCaffery

kirstenm@health.usyd.edu.au

Cite this as: BMJ 2010;340:b4491 doi:10.1136/bmi.b4491

\section{ABSTRACT}

Objective To assess which of three triage strategies for women with borderline abnormal cervical smear results in the best psychosocial outcomes.

Design Pragmatic, non-blinded, multicentre, randomised controlled trial.

Setting 18 family planning clinics across Australia, covering both urban and rural areas, between January 2004 and October 2006.

Participants Women aged $16-70$ years $(n=314)$ who attended routine cervical screening and received a borderline cervical smear.

Interventions Patients were randomly assigned to human papillomavirus (HPV) DNA testing $(n=104)$, a repeat smear test at six months $(n=106)$, or the patient's informed choice of either test supported by a decision aid $(n=104)$. Psychosocial outcomes were assessed at multiple time points over 12 months by postal questionnaire.

Main outcome measures We assessed health related quality of life (SF36 mental health subscale), cognitive effects (such as perceived risk of cervical cancer, intrusive thoughts), affective outcomes (general anxiety [state-trait anxiety inventory]), specific anxiety about an abnormal smear (cervical screening questionnaire), and behavioural outcomes (sexual health behaviour and visits to the doctor) over 12 months of follow-up. Results At two weeks, some psychosocial outcomes were worse for women allocated to HPV testing compared with those in the smear testing group (SF36 vitality subscale: $\mathrm{t}=-1.63, \mathrm{df}=131, \mathrm{P}=0.10$; intrusive thoughts $X^{2}=8.14$, $\mathrm{df}=1, \mathrm{P}<0.01)$. Over 12 months, distress about the abnormal smear was lowest in women allocated to HPV testing and highest in the repeat smear testing group $(t=-2.89, d f=135, P<0.01)$. Intrusive thoughts were highest in patients allocated to HPV testing (25\%, compared with $13 \%$ in the informed choice group; difference $=12 \%, 95 \% \mathrm{Cl}-1.1 \%$ to $25.1 \%$ ). Women in the HPV DNA group and the informed choice group were more satisfied with their care than women allocated to repeat smear testing.
Conclusions Although the psychosocial effect was initially worse for women allocated to HPV triage, over the full year of follow-up this intervention was better for women's psychosocial health than repeat smear testing. Offering informed choice could have a small advantage for cognitive outcomes, but in view of the additional effort and logistical complexity that this intervention requires, HPV testing alone can be justified for most women. Trial Registration actr.org.au Identifier: 12605000111673

\section{INTRODUCTION}

Despite development and use of the human papillomavirus (HPV) vaccine, cervical screening remains the primary method for the prevention of cervical cancer. Debate continues about the best strategies for the management of cervical abnormalities detected by screening. ${ }^{12}$ HPV DNA testing is a new option for the management of low grade and borderline cervical abnormalities, also known as atypical cells of undetermined significance (ASCUS) in the United States, or non-specific minor changes/possible low grade squamous intraepithelial lesions (LSIL) in Australia. This category accounts for about 3-4\% of all smear test results, and affects over 100000 women in the United Kingdom every year. ${ }^{3}$ Unlike the conventional management for this group (repeat cervical screening at 6 to 12 months), HPV triage testing can immediately identify women at higher or lower risk of having a more serious cervical abnormality who require colposcopic follow-up. HPV triage involves an immediate HPV DNA test with women who test HPV positive (indicating the presence of oncogenic HPV viral types), recommended for colposcopy. Since 2001, HPV triage has been recommended in the US for women with ASCUS, and its introduction within the cervical screening programme of the UK National Health Service is currently being implemented in sentinel sites across England and Wales (NHS Cervical Screening Programme HPV Sentinel Sites Implementation Project www.cancerscreening.nhs.uk/cervical/hpv-senti 
nel-sites.html). Its use in the Australian cervical screening programme is currently under consideration.

HPV triage testing has potential downsides. It could result in an explicit diagnosis of a sexually transmitted infection and an increased rate of referral to colposcopy, ${ }^{4}$ both of which are known to cause anxiety. ${ }^{5-8}$ Cross sectional and qualitative studies indicate increased psychological burden among women testing positive for HPV in triage and primary HPV screening, at least in the short term. ${ }^{578}$ Whether these potential psychological harms are offset by the faster follow-up and reduced waiting times offered by HPV triage testing is currently unknown.

The IMAP study (Improving Management of Abnormal Pap Smears) was designed to assess the psychosocial effect of HPV triage testing compared with conventional management by repeat smear testing for women with a borderline smear result over one year. Additionally, the study assessed the effect of informed choice on psychosocial wellbeing. Increasingly, informed choice is recognised as important within screening programmes. ${ }^{9-11}$ This process acknowledges that potential participants have the right to be informed of the benefits and harms of screening, and can therefore make their own informed decision about their management. The effect of informed choice in studies of screening and treatment suggests that there are short term benefits, but the evidence of long term outcomes for health and quality of life remains uncertain. ${ }^{12}$ The effects of informed choice beyond the initial period of decision making need to be ascertained. ${ }^{13}$

This study therefore set out to assess the effect of management by HPV triage or a repeat smear test, and the effect of informed choice of management (HPV triage or repeat smear testing) supported by a decision aid, compared with clinician directed management on psychosocial outcomes over a year for women with a borderline smear.

The study was done in Australia, which has had a national cervical screening programme in operation since 1991. Psychosocial outcomes included quality of life measures as well as measures of cognitive, emotional, and behavioural wellbeing.

\section{METHODS}

\section{Participants}

In all, 314 women aged 16 to 70 years who were attending routine cervical screening at family planning clinics across Australia were identified. All women had received a smear test result categorised as non-specific minor changes with or without HPV effect (koilocytosis). This category represented the closest Australian equivalent to the categories used in the UK and US of borderline and atypical cells of undetermined significance (ASCUS), and will be referred to using the UK terminology, borderline smear. Only women with an index borderline abnormality were included (that is, this was their first cervical abnormality detected, with no history of external visible genital warts within the past two years). Women who were pregnant or who became pregnant during the course of the study and those who were unable to complete a written questionnaire in English were excluded.

\section{Recruitment}

Participants were recruited from 18 clinics across Australia, covering urban and rural areas, between January 2004 and October 2006. Eligible women who matched the selection criteria were identified by a research nurse at each clinic and sent a study information booklet, an invitation letter, and consent form, along with the results of their smear test. Women then received a follow-up telephone call from a family planning research nurse. Women willing to participate returned their consent form to researchers at the University of Sydney and were recruited into the study.

\section{Design}

Participants were randomised centrally by the research team within each clinic in blocks of three. Randomisation was not blinded, but was concealed from clinic staff until allocation. Women allocated to the HPV triage group were asked to arrange an appointment for HPV testing at their local clinic as soon as possible. Women randomised to repeat smear testing were asked to schedule an appointment in six months. Women in the informed consent group were sent the decision aid describing the advantages and disadvantages of each management strategy (as described in McCaffery et al). ${ }^{14}$ They were then asked to choose their preferred test by completing a preference form and were advised to schedule a test appointment at their local clinic.

The decision aid was developed using the Ottawa framework. ${ }^{15}$ Outcomes of management were based on estimates from the Australian cervical screening programme and from the ASCUS-LSIL triage study (ALTS). ${ }^{16-18}$ Women were given information about each of the options and the characteristics of testing with respect to the timing of follow-up and the likelihood of referral to colposcopy (expressed as a natural frequency out of a denominator of 100 women). Information about the possible negative effect on quality of life for each treatment strategy was described qualitatively. For HPV triage this outcome was given as the possible diagnosis of an HPV infection, and for smear testing was described as the six month waiting period for a repeat test, which can cause anxiety in some women (see web appendix 1). Previous analysis of the decision aid indicated that women rated it highly $(82 \%$ indicated it was balanced, $99 \%$ reported "everything or most things" were clear, $85 \%$ indicated it was "about the right length", and $86 \%$ found it "very or somewhat" helpful $^{14}$ (www.psych.usyd.edu.au/cemped/communi cation.shtml).

\section{Clinical management}

All index smears were done using conventional testing methods. Women receiving HPV testing were required to attend their clinic for a swab using the Digene Hybrid Capture 2 HPV DNA test (Gaithersburg, MD, USA). 
Clinical management followed the ALTS protocol for follow-up (ALTS 2001). Women who tested positive for HPV were referred for colposcopy with a local public provider. Those who tested negative were recalled for a smear test at 12 months.

Women allocated to or who chose a repeat smear test were advised to re-attend at six months. Participants were subsequently managed according to the Australian guidelines current at the time of the study. ${ }^{19}$ At the six month smear, women with a normal or borderline result were recalled for a further repeat smear test six months later. Those with moderate dyskaryosis (cervical intraepithelial neoplasia grade 2 [CIN2]) or above were referred for colposcopy and women with mild dyskaryosis (CIN1) could choose either colposcopy or a repeat smear test.

\section{Measures}

Immediately after consent, participants were sent the first study questionnaire to assess their demographic, health, and psychological status. This questionnaire aimed to be as close as possible to the receipt of the index (first) abnormal test result. Psychosocial wellbeing was then assessed at regular time points over 12 months after triage testing (figure 1). Post-triage questionnaires were sent at two weeks and at three, six, and 12 months. Participants allocated to or who chose repeat smear testing received two additional questionnaires before their six month smear test. These additional questionnaires assessed waiting time anxiety at two and four months, and were scheduled around the same time as the two week and three months questionnaires in the HPV group. For all questionnaires a reminder letter and second copy of the questionnaire was sent to non-responders after two weeks. Women who failed to respond to the study questionnaires or did not attend their test were sent a non-attenders questionnaire (at three months after the last date of contact) to identify the reason.

The study measures were selected to reflect the multifaceted psychosocial consequences of an abnormal

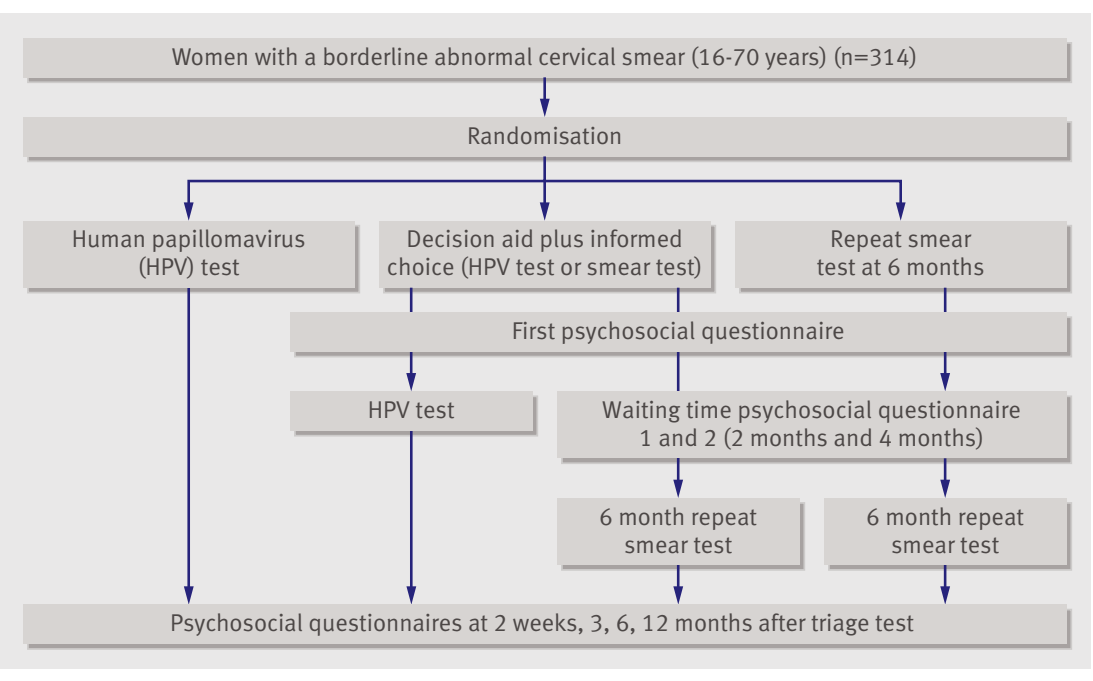

Fig 1| Randomised trial design and psychosocial assessment smear, with cognitive, emotional, and behavioural outcomes ${ }^{20}$ represented as secondary outcomes. The mental health component of the SF36 ${ }^{21}$ was used to provide a generic measure of quality of life and was seen as the primary outcome (figure 2). Demographic variables measured at the time of the first questionnaire included age, education, employment, marital and relationship status, children, and ethnicity. Health variables included smoking behaviour, oral contraceptive use, previous abnormal smear result, previous colposcopy, and number of sexual partners.

The cognitive measures assessed included perceived risk of cervical cancer, ${ }^{22}$ perceived seriousness of cervical cancer, worry about cervical cancer, ${ }^{23}$ intrusive thoughts about the abnormal smear results (measured using one item from the impact of events scale), ${ }^{24}$ satisfaction with health care in general, and women's satisfaction with the care received for their abnormal cervical smear. ${ }^{25}$

For emotional measures, we assessed anxiety using the six item abbreviated state trait anxiety inventory (STAI), ${ }^{26}$ and measured distress and concern specific to the abnormal smear using the cervical screening questionnaire ${ }^{23}$ and the psychosocial effects of abnormal Pap smears questionnaire (infectivity and relationships subscales). ${ }^{27}$ We also assessed self esteem. ${ }^{28}$

Behavioural measures included effect on sexual behaviour (sexual health) ${ }^{29}$ and help seeking behaviours, visits to a general practitioner (GP), and telephone calls to the family planning clinic for information and advice.

We assessed knowledge in the two week post-triage questionnaire to investigate the effect of the decision aid on the patients' understanding of their management options and their abnormal smear. The knowledge scale included 10 items, with four relating to understanding of key features of HPV (such as its link with cervical abnormalities and cancer, high risk and low risk HPV types, HPV latency, and prevalence). The remaining six items related to understanding of the abnormal cervical smear result, triage by smear testing, and colposcopy follow-up. The response categories were "true", "false", and "not sure", with correct answers scored as 1 and incorrect or unsure responses scored as 0 .

\section{Statistical methods}

The analyses were done on an intention to treat basis. We compared psychosocial outcomes across the three trial arms cross sectionally at two weeks after the triage test, and then longitudinally for nine months (from three months to 12 months after the index result) using an analysis based on area under the curve. There was loss to follow-up, with increasing loss as the length of followup management increased (see figure 3). Three participants changed treatment group. Two withdrew from the study after triage testing, and one did not complete any follow-up questionnaires after the first psychosocial questionnaire. These women were included in the sensitivity analysis according to the arm they were originally randomised to. 


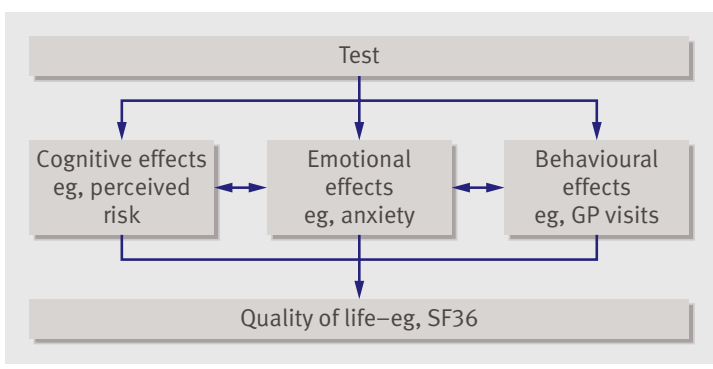

Fig 2 | Framework for understanding and assessing psychosocial effects.

Cross sectional analysis

To compare the scores two weeks after initial screening, a global ANOVA F-test was used, allowing for the unbalanced design, to assess if any of the means were different between groups. Only variables where the ANOVA was statistically significant (at $\mathrm{P}<0.1$ ) had the pairwise analysis done, using $t$ tests with a significance level of $\mathrm{P}<0.05$ and with $^{30}$ adjustment for unequal variances. Differences significant at the 0.10 level have been reported. Non-parametric tests (Kruskal-Wallis and Wilcoxon) were done to ensure that the results were robust to non-normality and differences in variances between the groups. For the ordinal outcomes with less than five categories, $\chi^{2}$ tests for the difference in proportions were used for the global test with pairwise comparisons if $\mathrm{P}<0.1$.

\section{Longitudinal analysis}

The design of the study comparing HPV testing, which happened soon after the index abnormal smear result, with the six month follow-up smear test had a highly unbalanced pre-triage waiting time. The effect of the different waiting periods was expected to be a key component of potential psychosocial difference and would not be captured in the two week follow-up cross sectional comparison. Similarly, a cross sectional comparison at 12 months post-triage was not appropriate, since for the HPV group this represents 12-13 months from the index abnormal smear and for the repeat testing group represents around 18 months. We would therefore expect patients in the repeat smear testing group to have better psychosocial outcomes. To assess the effect of the different waiting periods, as well as the time period after the triage test, an area under the curve analysis was used to obtain an average per day for all the psychosocial outcomes (see web appendix 2). The area under the curve method allows for variation in follow-up schedules for the different study groups and also variation in the times at which women completed questionnaires. The area was calculated between 90 and 365 days from the index result using linear interpolation and linear extrapolation if required (web appendix 2). This time period was chosen to enable comparison between the groups at 12 months of follow-up from the index abnormal result, and to minimise the need for extrapolation of questionnaire data. Only participants with information at the three, six, or 12 months post-triage questionnaire and with at least two measurements on the outcome of interest were included in the area analysis. For example, for the measure for cervical screening specific distress, the area under the curve analysis was based on four or more measurements for 175 women, three measurements for 21 women, and two measurements in only 13 women, a total of 209 women. This method was used to minimise extrapolation of data from early time points where psychological scores were worst. The area under the curve was then divided by the 275 days (365-90 days) of follow-up to represent the average of the psychosocial outcomes per day.

To compare mean scores across the groups, we used the same methods described for the cross sectional analysis, with a global ANOVA F test followed by pairwise comparisons using $t$ tests and $\chi^{2}$ statistic for categorical outcomes. Effect size for the SF36 mental health component subscales ${ }^{3132}$ were calculated using both the sample standard deviation and Australian population standard deviation. ${ }^{33}$ Findings were similar using either method, so the effect sizes using Australian population data are reported.

\section{Sensitivity analysis}

The area was divided into three time intervals. Period 1 (days 90-160) indicated the time at which most women (over 90\%) receiving the HPV screening were tested. Period 2 (days 161-320) represented the time at which over $90 \%$ of women allocated to or choosing repeat cervical smear received their test. Period 3 (days 321365 ) represented the period at which most women in both arms had completed testing. The period scores were then plotted across time by study group to assess whether effects varied by time, particularly for the last period where extrapolation was more likely.

Around two thirds of the sample were included in the area analysis. To assess the robustness to the inclusion and exclusion criteria, sensitivity analysis was done first, including all participants who had at least two data points but did not have an appropriate end point (follow-up at three, six, or 12 months after testing, 259 women, $82 \%$ of the total sample). All participants with only one data point were then included in the analysis by assuming that their observed value remained constant with time (304 women, 97\% of the total sample). The results of the sensitivity analysis showed no material differences to the interpretation of the study findings.

\section{Sample size}

We aimed to recruit 120 participants per randomised arm, to retain 100 per group after allowing for some loss to follow-up. This sample size was sufficient to detect differences in proportions between trial arms of $5 \%$ versus $18 \% ; 10 \%$ versus $26 \% ; 20 \%$ versus $39 \%$ at the 0.05 significance level with $80 \%$ power. The power calculation was based on differences in binary outcomes (proportions), with the assumption that for continuous outcomes, we would have more power to detect differences.

All the analyses were done using SAS version 9.1. 


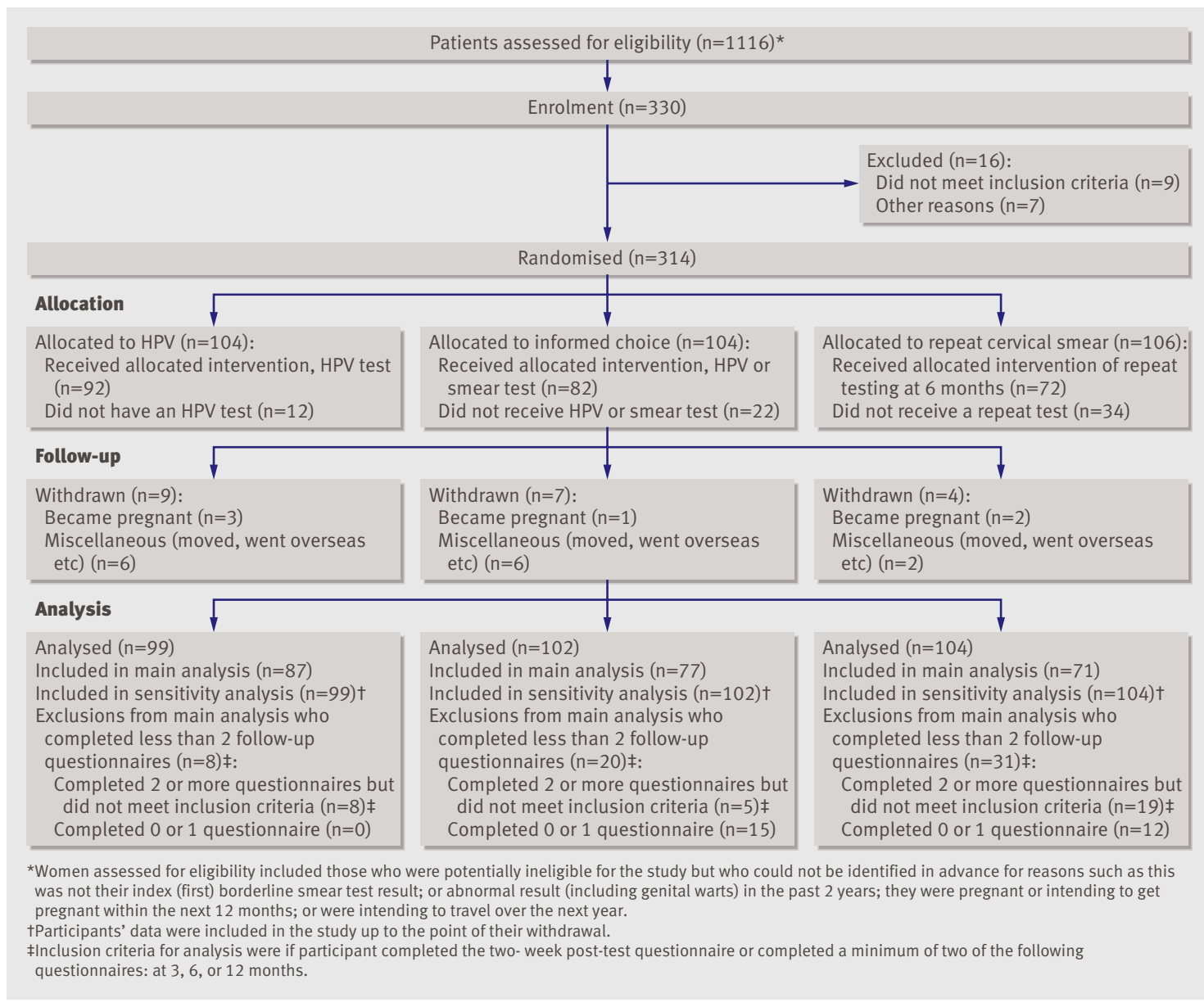

Fig 3 | Patient recruitment and retention

\section{RESULTS}

The trial took place between January 2004 and August 2007. 330 women were enrolled in the study, with 16 women excluded as not meeting the eligibility criteria. Three hundred and fourteen women were randomised to the three trial arms. In total, $261(83 \%)$ participants completed at least two psychological questionnaires and $235(75 \%)$ participants met the criteria for inclusion in the analysis.

Table 1 shows the demographic and health characteristics of the sample included in the analysis. Characteristics were similar across each of the groups, with some small imbalances in variables relating to smear test result, previous experience of an abnormality, and relationship and sexual history (index test result, previous abnormal smear test, previous colposcopy, current relationship status, and number of sexual partners). The potential confounding by these variables was assessed in all subsequent analyses. Including them in the models did not affect the interpretation of the results, therefore we chose to present the simpler models.

In the informed choice group, $61(64 \%)$ women chose HPV triage and $35(36 \%)$ chose repeat smear testing. ${ }^{14}$ Of the 151 women who received the HPV test, $57(38 \%)$ tested positive and $94(62 \%)$ tested negative.

The distribution of the psychosocial measures assessed in the two week questionnaire are described in table 2 with comparative data given from other relevant samples where available. The SF36 mental health component scores were lower (worse) than those reported in a study of Australian women with a minor medical condition (such as allergies, back problems, arthritis, rheumatism, or bronchitis) but higher (better) than women with a serious medical condition (including heart conditions, stroke, and cancer). ${ }^{34}$

The impact of each category of the psychosocial outcomes at two weeks and over one year is described below and presented in tables 3 and 4 .

\section{Effect on health related quality of life}

At two weeks after triage, health related quality of life was worse in the HPV testing group. There was weak evidence of an effect on the SF36 vitality subscale $(\mathrm{F}=2.46, \mathrm{df}=2,196, \mathrm{P}=0.09)$ for women in the HPV group compared with the cervical smear group $(\mathrm{t}=$ $-1.63, \mathrm{df}=131, \mathrm{P}=0.1$; effect size $=0.33$ ) and compared with the informed choice group $(\mathrm{t}=-2.00, \mathrm{df}=141$, $\mathrm{P}=0.05$, effect size 0.27 ). Over a year, there were consistently higher scores on all the SF36 subscales in the 
informed choice group than in both the other groups; however, these were not significant. Health related quality of life scores generally improved in all the subscales over the year in all trial groups.

At two weeks after testing, women in the HPV arm reported poorer outcomes on the cognitive measure of intrusive thoughts $(57 \%$ (44 of 77) $v 43 \%$ (28 of 65 ) in the informed choice group and $32 \%$ (18 of 56 ) in the smear test group ). Women in the HPV arm had more intrusive thoughts than the other groups (HPV $v$ smear test: $\chi^{2}=8.14, \mathrm{df}=1, \mathrm{P}<0.01 ; \mathrm{HPV} v$ informed choice: $\left.\chi^{2}=2.79, \mathrm{df}=1, \mathrm{P}=0.09\right)$. Over the year, the intrusive thoughts were highest in the HPV group (25\% 19 of 75)) and were lowest in the informed choice group $(13 \%$; table 4$)$ with a $12 \%$ difference between the two arms $(95 \% \mathrm{CI}-1.1 \%$ to $25.1 \%)$. Worries about cervical cancer were similar between the trial arms at 2 weeks, but over the year showed greater variation, with the lowest levels of worry, in the informed choice group ( $8 \%$ (5 of 59) $v 16 \%$ (12 of 74) in the HPV group and $15 \%$ (6 of 41$)$ in the smear test group). Again these differences were not significant $(8 \%$ difference HPV $v$ informed choice, $95 \% \mathrm{CI}-3.3$ to $18.7 ; 7 \%$ difference informed choice $v$ smear test, $95 \%$ CI $-19.1 \%$ to $6.8 \%$ ). By contrast, women's satisfaction with their targeted care for their cervical abnormality was higher in the HPV triage and informed choice groups than in the cervical smear group at two weeks (HPV and smear test: $\mathrm{t}=1.96, \mathrm{df}=129, \mathrm{P}=0.05 ; \mathrm{HPV}$ and informed choice: $\mathrm{t}=2.37, \mathrm{df}=118, \mathrm{P}=0.02$ ). These scores remained significantly different over the year for satisfaction with health care in general (fig $4 ; \mathrm{HPV} v$ smear test: $\mathrm{t}=2.70, \mathrm{df}=136, \mathrm{P}=0.01$; informed choice $v$ smear test: $\mathrm{t}=2.11, \mathrm{df}=135, \mathrm{P}=0.04)$ and satisfaction with the care received for the abnormal smear (HPV $v$ smear test: $\mathrm{t}=2.85, \mathrm{df}=138, \mathrm{P}=0.01$ ).

For the emotional outcomes, there were no significant differences between the groups at 2 weeks after testing, although the HPV arm had slightly worse scores across many of the measures. Over the year, there was an improvement in emotional outcomes in all groups. However, the HPV arm had lowest scores on the cervical screening specific distress measure (that is, were least distressed) over the course of the year (fig 5). There was evidence of a difference in specific distress scores over the year of follow-up $(\mathrm{F}=4.35, \mathrm{df}=2$, $206, \mathrm{P}=0.01$ ), and in the pairwise comparisons the distress scores were significantly lower in the HPV arm than in the smear testing arm (16.6 $v 18.4, \mathrm{t}=-2.89$, $\mathrm{df}=135, \mathrm{P}<0.01)$.

Of the behavioural measures, there were few differences between groups on the sexual health scale or in GP visits or calls to family planning clinics over the course of follow-up. There was a small increase in the number of GP visits in the HPV arm at two weeks; however, this finding appears to be driven by a few women in the HPV arm having a high number of GP visits compared with those in the informed choice group. The lower quartile, median, and upper quartile number of GP visits was the same across all three groups $-0,0$, and 1 , respectively — suggesting that for most women, the number of GP visits at two weeks is the same across the study.

We compared women's knowledge and understanding of HPV and smear testing between the informed choice group and the allocated treatment groups. Women in the informed choice arm had higher total knowledge scores than women in either of the other groups, which indicates that the decision aid was useful (mean score for informed choice 8.1 v HPV 7.3 and cervical smear 7.2 out of $10, \mathrm{~F}=4.97, \mathrm{df}=2,160$ $\mathrm{P}<0.01)$. We examined knowledge items relating to HPV triage and smear testing separately to examine whether this affected the results (table 5). Women in the informed choice group had higher scores on the smear testing items than in the other groups. However, their knowledge scores on the HPV testing items were not significantly higher than women in the HPV triage arm, indicating that women allocated to HPV triage had also become reasonably well informed about their test.

\section{DISCUSSION}

Our findings suggest that although psychosocial outcomes for women receiving HPV triage are worse in the short term, over 12 months the outcomes seem to be better than those seen with conventional management by repeat smear testing. Two weeks after triage testing, psychosocial outcomes were poorer for women who received HPV testing than for those in the repeat smear testing or informed choice groups, with lower health related quality of life scores on the SF36 vitality subscale, and with a small effect size of 0.27 (small <0.3). Women allocated to HPV testing also had more intrusive thoughts about the abnormal result than the other groups. However, when outcomes were assessed over a full year, the psychosocial burden was worse for those participants who waited six months for a repeat smear. The HPV and informed choice groups had better psychosocial outcomes than the repeat smear group, with a significant effect on the specific distress measure for the HPV testing group compared with the smear group. Both the HPV and informed choice groups also rated satisfaction with management consistently higher than did women in the smear testing group.

Our findings suggest that HPV triage has an initial negative effect on psychosocial wellbeing but that this effect is quickly resolved. By contrast, the psychosocial burden of triage by repeat smear testing remained higher for longer and resulted in a greater total burden on the specific measure of distress for cervical screening. In a cross sectional study, Maissi et al ${ }^{535}$ indicated that short term effects of management (assessed at four weeks after triage) were worse for women receiving HPV testing than for those who were not tested (receiving a repeat smear test only). At six months, this difference had disappeared. Maissi found a higher level of concern about sexual health in the HPV positive group at six months, but concerns about the test result itself were highest in the group with an abnormal smear who were not tested for HPV. However, these findings are 
Table 1|Sociodemographic and health characteristics

\begin{tabular}{|c|c|c|c|c|c|c|c|}
\hline & \multicolumn{2}{|c|}{ HPV } & \multicolumn{2}{|c|}{ Informed choice } & \multicolumn{2}{|c|}{ Cervical smear } & \multirow{2}{*}{$\begin{array}{c}\text { Total } \\
\mathrm{n}\end{array}$} \\
\hline & $n$ & $\%$ & $n$ & $\%$ & $n$ & $\%$ & \\
\hline \multicolumn{8}{|l|}{ Age (years) } \\
\hline $30+$ & 56 & 65.1 & 47 & 61.0 & 50 & 71.4 & 153 \\
\hline$\ll 30$ & 30 & 34.9 & 30 & 39.0 & 20 & 28.6 & 80 \\
\hline \multicolumn{8}{|l|}{ Education } \\
\hline Secondary education & 35 & 42.2 & 18 & 24.3 & 25 & 35.7 & 78 \\
\hline Tertiary education & 17 & 20.5 & 20 & 27.0 & 17 & 24.3 & 54 \\
\hline University & 31 & 37.3 & 36 & 48.6 & 28 & 40.0 & 95 \\
\hline \multicolumn{8}{|l|}{ Employment } \\
\hline Full time & 35 & 42.2 & 38 & 50.7 & 34 & 48.6 & 107 \\
\hline Other & 48 & 57.8 & 37 & 49.3 & 36 & 51.4 & 121 \\
\hline \multicolumn{8}{|l|}{ Marital status } \\
\hline Married/ de facto & 43 & 51.8 & 41 & 54.7 & 32 & 45.1 & 116 \\
\hline Single/divorced/ separated/ widowed & 40 & 48.2 & 34 & 45.3 & 39 & 54.9 & 113 \\
\hline \multicolumn{8}{|l|}{ Children } \\
\hline Yes & 51 & 60.7 & 35 & 46.7 & 34 & 47.9 & 120 \\
\hline No & 33 & 39.3 & 40 & 53.3 & 37 & 52.1 & 110 \\
\hline \multicolumn{8}{|l|}{ Born in Australia } \\
\hline Yes & 66 & 78.6 & 63 & 84.0 & 57 & 80.3 & 186 \\
\hline No & 18 & 21.4 & 12 & 16.0 & 14 & 19.7 & 44 \\
\hline \multicolumn{8}{|l|}{ Non-English speaking background } \\
\hline Yes & 13 & 15.7 & 7 & 9.3 & 7 & 9.9 & 27 \\
\hline No & 70 & 84.3 & 67 & 89.3 & 59 & 83.1 & 196 \\
\hline \multicolumn{8}{|l|}{ Index smear test } \\
\hline HPV effect & 12 & 13.8 & 7 & 9.2 & 12 & 16.9 & 31 \\
\hline No HPV effect & 75 & 86.2 & 69 & 90.8 & 59 & 83.1 & 203 \\
\hline \multicolumn{8}{|l|}{ Contraceptive pill } \\
\hline Yes & 25 & 30.1 & 31 & 41.9 & 28 & 39.4 & 84 \\
\hline No & 58 & 69.9 & 43 & 58.1 & 43 & 60.6 & 144 \\
\hline \multicolumn{8}{|l|}{ Number of sexual partners } \\
\hline 1 & 16 & 19.0 & 11 & 14.7 & 10 & 14.1 & 37 \\
\hline 2 to 5 & 29 & 34.5 & 25 & 33.3 & 22 & 31.0 & 76 \\
\hline $6+$ & 39 & 46.4 & 39 & 52.0 & 39 & 54.9 & 117 \\
\hline \multicolumn{8}{|l|}{ Relationship status } \\
\hline $\begin{array}{l}\text { In current } \\
\text { relationship }\end{array}$ & 62 & 73.8 & 64 & 85.3 & 55 & 78.6 & 181 \\
\hline $\begin{array}{l}\text { No current } \\
\text { relationship }\end{array}$ & 22 & 26.2 & 11 & 14.7 & 15 & 21.4 & 48 \\
\hline \multicolumn{8}{|l|}{ Previous abnormal smear test } \\
\hline Yes & 36 & 43.4 & 20 & 26.7 & 23 & 32.9 & 79 \\
\hline No & 47 & 56.6 & 55 & 73.3 & 47 & 67.1 & 149 \\
\hline \multicolumn{8}{|l|}{ Previous colposcopy } \\
\hline Yes & 15 & 17.2 & 12 & 15.6 & 16 & 22.5 & 43 \\
\hline No & 38 & 43.7 & 25 & 32.5 & 25 & 35.2 & 88 \\
\hline No response & 34 & 39.1 & 40 & 51.9 & 30 & 42.3 & 104 \\
\hline \multicolumn{8}{|l|}{ Smoking status } \\
\hline Yes & 20 & 23.8 & 19 & 25.7 & 17 & 23.9 & 56 \\
\hline No & 64 & 76.2 & 55 & 74.3 & 54 & 76.1 & 173 \\
\hline
\end{tabular}

limited by the use of a cross sectional design. Our study showed, using a randomised trial method and comparing psychosocial outcomes for a year, that HPV triage actually caused less screening specific distress overall and resulted in greater satisfaction with management than repeat testing. This finding highlights the importance of long term follow-up of psychosocial outcomes.
Multiple outcomes were included in this study in order to comprehensively assess the various psychosocial effects of management. Examination of multiple independent outcomes can lead to spurious significant findings, and increase type I errors. However, P value adjustment when items are correlated, as the psychosocial variables were in this study, is likely to be overly 
Table 2 Distribution of psychosocial measures in the two week questionnaire

\begin{tabular}{|c|c|c|c|c|c|c|c|c|c|}
\hline & & $\mathrm{n}$ & $\begin{array}{l}\text { Possi- } \\
\text { ble } \\
\text { range }\end{array}$ & Min & $\begin{array}{l}\text { Med- } \\
\text { ian }\end{array}$ & IQR & Max & $\begin{array}{l}\text { Mean } \\
\text { (SD) }\end{array}$ & $\begin{array}{l}\text { Relevant comparison scores where } \\
\text { available }\end{array}$ \\
\hline SF36: mental health combined score & $\begin{array}{l}\text { Combined mental health subscales } \\
\text { score }\end{array}$ & 196 & $0-100$ & 11.5 & 48.9 & $\begin{array}{l}38.6- \\
54.5\end{array}$ & 65.4 & $\begin{array}{l}45.8 \\
(11.5)\end{array}$ & $\begin{array}{l}\text { Population norms for Australian women } \\
\text { aged } 25-64 \text { years range from } 48.3 \text { to } \\
\text { 50.6. (ABS 1995) }\end{array}$ \\
\hline SF36: vitality & $\begin{array}{l}\text { Feeling energetic and full of life versus } \\
\text { tired and worn out }\end{array}$ & 199 & $0-100$ & 0 & 55 & $40-65$ & 100 & $\begin{array}{l}52.4 \\
(18.7)\end{array}$ & $\begin{array}{l}{ }^{*} \text { Medical conditions: } \text { none }=73.54 ; \\
\text { minor }=65.74 ; \text { serious }=54.98 ; \\
\text { depression }=62.35\end{array}$ \\
\hline SF36: social functioning & $\begin{array}{l}\text { Extent physical or emotional problems } \\
\text { interfering with normal social activities }\end{array}$ & 199 & $0-100$ & 12.5 & 100 & $75-100$ & 100 & $\begin{array}{l}81.9 \\
(22.8)\end{array}$ & $\begin{array}{l}\text { Medical conditions: none=95.76; } \\
\text { minor=90.5; serious=78.87; } \\
\text { depression }=90.07\end{array}$ \\
\hline SF36: role emotional & $\begin{array}{l}\text { Extent emotional problems interfere } \\
\text { with work or daily activities }\end{array}$ & 196 & $0-100$ & 0 & 100 & $\begin{array}{l}66.7- \\
100\end{array}$ & 100 & $\begin{array}{l}77.2 \\
(35.6)\end{array}$ & $\begin{array}{l}\text { Medical conditions: none=96.34; } \\
\text { minor }=88.26 ; \text { serious }=74.85 \\
\text { depression }=87.86\end{array}$ \\
\hline SF36: mental health & $\begin{array}{l}\text { General mental health including } \\
\text { depression and anxiety }\end{array}$ & 199 & $0-100$ & 20 & 72 & $60-84$ & 100 & $\begin{array}{l}70.3 \\
(16.3)\end{array}$ & $\begin{array}{l}\text { Medical conditions: } \text { none }=85.72 ; \\
\text { minor }=83.61 ; \text { serious }=68.97 \\
\text { depression }=83.78\end{array}$ \\
\hline Perceived severity† & $\begin{array}{l}\text { Perceived severity of an abnormal } \\
\text { smear }\end{array}$ & 192 & $0-10$ & 0 & 5 & $3-7$ & 10 & $\begin{array}{l}4.9 \\
(2.2)\end{array}$ & - \\
\hline Perceived risk of cervical cancer† & $\begin{array}{l}\text { Perceived risk of cervical cancer } \\
\text { compared with others }\end{array}$ & 198 & $1-7$ & 1 & 4 & $2-5$ & 7 & $\begin{array}{l}3.7 \\
(1.6)\end{array}$ & - \\
\hline Intrusive thoughts $†$ & $\begin{array}{l}\text { Thought about abnormal smear when I } \\
\text { didn't want to }\end{array}$ & 198 & $1-4$ & 1 & 2 & $2-3$ & 4 & $\begin{array}{l}2.3 \\
(0.9)\end{array}$ & - \\
\hline Worry† & Worry about getting cervical cancer & 196 & $1-4$ & 1 & 2 & $2-2$ & 4 & $\begin{array}{l}2.1 \\
(0.8)\end{array}$ & - \\
\hline Satisfaction generally & Satisfaction with healthcare generally & 197 & $4-20$ & 4 & 15 & $13-16$ & 20 & $\begin{array}{l}14.6 \\
(2.9)\end{array}$ & - \\
\hline Satisfaction with care & $\begin{array}{l}\text { Satisfaction with care for the abnormal } \\
\text { smear }\end{array}$ & 196 & $0-10$ & 0 & 9 & $8-10$ & 10 & $\begin{array}{l}8.3 \\
(1.9)\end{array}$ & - \\
\hline Anxiety (STAl) † & $\begin{array}{l}\text { State of anxiety (eg, calm, tense, } \\
\text { relaxed) }\end{array}$ & 187 & $20-80$ & 20 & 36 & $\begin{array}{l}23.3- \\
36.3\end{array}$ & 80 & $\begin{array}{l}36.3 \\
(13)\end{array}$ & $\begin{array}{l}\text { Population norm for women is } 35 \text {. } \\
\text { Scores more than } 49 \text { seen in women } \\
\text { with anxiety disorder }\end{array}$ \\
\hline Cervical screening questionnaire $†$ & $\begin{array}{l}\text { Distress relating to abnormal smear, } \\
\text { including worries about fertility, } \\
\text { cancer, gynaecological health }\end{array}$ & 190 & $0-36$ & 6 & 18 & $15-21$ & 29 & $\begin{array}{l}18.3 \\
(4.7)\end{array}$ & $\begin{array}{l}\text { Smear result normal=8.9; smear result } \\
\text { abnormal or unsatisfactory and HPV } \\
\text { positive }=17 \ddagger\end{array}$ \\
\hline PEAPS Q: infectivity† & $\begin{array}{l}\text { Worry about infectivity of abnormal } \\
\text { smear to sexual partners }\end{array}$ & 179 & $2-10$ & 2 & 2 & $2-4$ & 10 & $\begin{array}{l}3 \\
(1.8)\end{array}$ & - \\
\hline PEAPS Q: relationships $†$ & $\begin{array}{l}\text { Worry about effect on sexual } \\
\text { relationships of abnormal smear }\end{array}$ & 180 & $3-15$ & 3 & 3 & $3-5$ & 15 & $\begin{array}{l}4.5 \\
(2.5)\end{array}$ & - \\
\hline Relationship concerns & $\begin{array}{l}\text { Worries about current, previous, and } \\
\text { future sexual partners }\end{array}$ & 151 & $3-15$ & 3 & 9 & $9-9$ & 13.5 & $\begin{array}{l}9.2 \\
(1.5)\end{array}$ & - \\
\hline Self esteem & General self esteem & 196 & $10-40$ & 13.3 & 30 & $29-34$ & 40 & $\begin{array}{l}30.9 \\
(4.5)\end{array}$ & - \\
\hline Sexual health & $\begin{array}{l}\text { Interest in sex, frequency and negative } \\
\text { feelings about sex }\end{array}$ & 174 & $3-15$ & 3 & 9 & $7.5-9$ & 15 & $\begin{array}{l}8.5 \\
(2.1)\end{array}$ & - \\
\hline
\end{tabular}

$\mathrm{IQR}=$ interquartile range, STAI=state-trait anxiety inventory, PEAPS Q=psychosocial effects of abnormal Pap smears questionnaire.

${ }^{*}$ Mean scores for comparison groups differing in medical and psychiatric conditions, no medical conditions, minor medical conditions, serious medical conditions, depression. ${ }^{34}$

†Higher scores indicate poorer psychological outcomes. For all other measures, higher scores indicate better psychological outcomes.

$\ddagger$ We included an additional response category into this scale since it has previously been criticised for having unbalanced response categories.

conservative and also lead to an increase in type II errors resulting in a loss of power to detect true effects. Hence, we did not adjust for multiple outcomes in the current study. ${ }^{36}$ We highlight that the cognitive and emotional items that show significant differences between groups in the one year analysis were highly specific to the experience and concerns of an abnormal cervical smear result, as assessed by the cervical screening questionnaire measure (which includes concerns about fertility, gynaecological health, and cervical cancer), and the intrusive thoughts measure, which assessed frequency of thoughts women had about their abnormal smear results.

A randomised trial by Kitchener et $\mathrm{al}^{37}$ examined the psychological effect of primary HPV testing. The authors compared short term psychological and psychosexual outcomes at two weeks between women who were either given or not given their HPV test results. There were almost no differences in outcomes between the two groups. The findings indicated a net neutral effect of HPV testing in the short term; however, there are currently no long term data available for the outcomes from this trial.

Our results suggest that the effect of informed choice of management supported by a decision aid is uncertain. At two weeks after testing, the informed choice group had significantly better psychosocial outcomes than the HPV testing group, as measured by the SF36 vitality subscale, with a moderate effect size (0.33). 
Table $3 \mid$ Psychosocial outcomes at two weeks after triage

\begin{tabular}{|c|c|c|c|c|c|c|c|}
\hline & \multicolumn{3}{|c|}{ Trial arm mean scores } & \multirow[b]{2}{*}{ Overall $P$ value } & \multicolumn{3}{|c|}{ P value for pairwise comparisons* } \\
\hline & HPV & IC & RS & & HPV $v$ RS & HPV $v$ IC & RS $v$ IC \\
\hline \multicolumn{8}{|l|}{ Quality of life } \\
\hline $\begin{array}{l}\text { SF36: mental health } \\
\text { combined score }\end{array}$ & 44.3 & 47.0 & 46.3 & 0.35 & - & - & - \\
\hline Vitality & 48.7 & 55.2 & 54.1 & 0.09 & 0.10 & 0.05 & - \\
\hline Social function & 79.4 & 84.7 & 82.1 & 0.39 & - & - & - \\
\hline Role emotional & 74.3 & 80.3 & 77.4 & 0.61 & - & - & - \\
\hline Mental health & 68.5 & 71.3 & 71.6 & 0.46 & - & - & - \\
\hline \multicolumn{8}{|l|}{ Cognitive } \\
\hline Perceived severity† & 4.9 & 5.0 & 4.8 & 0.91 & - & - & - \\
\hline Perceived risk† & 3.5 & 3.9 & 3.8 & 0.24 & - & - & - \\
\hline Intrusive thoughtsł‡ & $57 \%$ & $43 \%$ & $32 \%$ & 0.02 & $<0.01$ & 0.09 & - \\
\hline Worrył‡ & $25 \%$ & $23 \%$ & $24 \%$ & 0.98 & - & - & - \\
\hline Satisfaction generally & 14.5 & 15.1 & 14.2 & 0.22 & - & - & - \\
\hline Satisfaction with care & 8.5 & 8.6 & 7.8 & 0.04 & 0.06 & - & 0.02 \\
\hline \multicolumn{8}{|l|}{ Emotional } \\
\hline Anxiety (STAI)† & 11.5 & 10.5 & 10.6 & 0.25 & - & - & - \\
\hline Distress (CSQ)† & 18.7 & 17.9 & 18.2 & 0.62 & - & - & - \\
\hline PEAPS-Q: infectivity† & 3.1 & 3.0 & 2.9 & 0.68 & - & - & - \\
\hline $\begin{array}{l}\text { PEAPS-Q: } \\
\text { relationships† }\end{array}$ & 4.7 & 4.5 & 4.3 & 0.74 & - & - & - \\
\hline Relationship concern & 9.2 & 9.4 & 9.0 & 0.39 & - & - & - \\
\hline Self esteem & 30.5 & 31.2 & 31.2 & 0.53 & - & - & - \\
\hline \multicolumn{8}{|l|}{ Behavioural } \\
\hline Sexual health & 8.5 & 8.7 & 8.5 & 0.88 & - & - & - \\
\hline Visits to GP/doctor§ & $0(1)$ & $0(1)$ & $0(1)$ & 0.08 & - & 0.02 & - \\
\hline $\begin{array}{l}\text { Calls to family } \\
\text { planning clinic§ }\end{array}$ & $0(1)$ & $0(0)$ & $0(0.5)$ & 0.55 & - & - & - \\
\hline \multicolumn{8}{|c|}{$\begin{array}{l}\text { RS=repeat smear, IC=informed choice, STAI=state-trait anxiety inventory, CSQ=cervical screening questionnaire, PEAPS-Q=psychosocial eff } \\
\text { abnormal Pap smears questionnaire. } \\
\text { F test (ANOVA with unbalanced design) used for all continuous variables. } \\
\text { *Pairwise comparisons were made only if } P<0.1 \text {. } \\
\text { †Higher scores represent poorer psychological wellbeing. } \\
\$ \mathrm{X}^{2} \text { test (independent proportions) used for categorical variables. } \\
\S \text { Median (interquartile range) number of visits or calls per questionnaire and non-parametric Kruskal-Wallis and Wilcoxon tests reported. }\end{array}$} \\
\hline
\end{tabular}

However, although scores in the informed choice arm were better on many of the psychosocial measures over 12 months compared to the other trial arms, scores were not significantly different, and effect sizes all fell within the small range $(<0.3)$. The cognitive measure, intrusive thoughts, showed a notable difference compared with HPV testing (12\%) over 12 months. Although not significant, the confidence intervals indicate that informed choice could offer an advantage to this outcome over HPV testing. Worry about cervical cancer demonstrated a similar although weaker pattern.

We conclude that offering women an informed choice offers uncertain benefit compared with HPV triage over 12 months, with the caveat that there might potentially be an advantage of informed choice on the cognitive outcomes, intrusive thoughts, and worry. Informed choice is also likely to be better than allocating women directly to repeat smear testing, which had the worst psychosocial outcomes. Women in the informed choice group had significantly higher overall knowledge scores than the other groups, which might be an important benefit. However, in view of the extra effort and cost that informed choice requires with respect to providing alternative services, it may or may not be seen as worthwhile for these outcomes.

Importantly, the knowledge measure also indicated that women in the HPV arm became well informed about HPV triage and the important characteristics of HPV and its association with cervical cancer. All women testing HPV positive in the study were provided with a high quality information leaflet (see web appendix 3) provided by the New South Wales Cervical Screening Program. This factor might have reduced some of the anxiety in the HPV group. Previous research has found anxiety and distress about the HPV test result is associated with poor understanding and confusion about HPV infection, and that poor understanding is often widespread among women undergoing HPV testing. ${ }^{53839}$

We know of only one previous study offering women choice in management of borderline cervical abnormalities. This study offered women the choice between a repeat smear test or immediate colposcopy, 
Table 4 |Psychosocial outcomes over one year

\begin{tabular}{|c|c|c|c|c|c|c|c|}
\hline & \multicolumn{3}{|c|}{ Trial arm mean scores } & \multirow[b]{2}{*}{ Overall $P$ value } & \multicolumn{3}{|c|}{ P value for pairwise comparisons* } \\
\hline & HPV & IC & RS & & HPV $v$ RS & HPV $v$ IC & RS $v$ IC \\
\hline \multicolumn{8}{|l|}{ Quality of life } \\
\hline $\begin{array}{l}\text { SF36: mental health } \\
\text { combined score }\end{array}$ & 46.2 & 48.5 & 45.5 & 0.16 & - & - & - \\
\hline Vitality & 52.8 & 57.1 & 52.5 & 0.18 & - & - & - \\
\hline Social function & 81.6 & 86.7 & 82.4 & 0.17 & - & - & - \\
\hline Role emotional & 80.2 & 83.1 & 75.7 & 0.23 & - & - & - \\
\hline Mental health & 70.3 & 74.0 & 70.2 & 0.18 & - & - & - \\
\hline \multicolumn{8}{|l|}{ Cognitive } \\
\hline Perceived severity $†$ & 4.8 & 4.7 & 4.9 & 0.92 & - & - & - \\
\hline Perceived risk† & 3.6 & 3.5 & 3.8 & 0.51 & - & - & - \\
\hline Intrusive thoughtst & $25 \%$ & $13 \%$ & $17 \%$ & 0.19 & - & - & - \\
\hline Worry†t & $16 \%$ & $8 \%$ & $15 \%$ & 0.4 & - & - & - \\
\hline Satisfaction generally & 14.5 & 14.4 & 13.5 & 0.03 & 0.01 & - & 0.03 \\
\hline Satisfaction with care & 8.4 & 8.0 & 7.6 & 0.02 & 0.01 & - & - \\
\hline \multicolumn{8}{|l|}{ Emotional } \\
\hline Anxiety (STAl)† & 10.9 & 10.5 & 11.4 & 0.27 & - & - & - \\
\hline CSQ (distress)† & 16.6 & 17.5 & 18.4 & 0.01 & $<0.01$ & - & - \\
\hline PEAPS-Q: infectivity $\dagger$ & 2.7 & 2.8 & 2.5 & 0.53 & - & - & - \\
\hline $\begin{array}{l}\text { PEAPS-Q: } \\
\text { relationships† }\end{array}$ & 4.1 & 4.0 & 4.1 & 0.99 & - & - & - \\
\hline Relationship concern & 8.7 & 9.1 & 9.0 & 0.15 & - & - & - \\
\hline Self esteem & 31.4 & 31.2 & 31.1 & 0.92 & - & - & - \\
\hline \multicolumn{8}{|l|}{ Behavioural } \\
\hline Sexual health & 9.1 & 8.7 & 8.6 & 0.11 & - & - & - \\
\hline Visits to GP/doctor§ & $0(0.67)$ & $0(0.67)$ & $0.33(0.75)$ & 0.23 & - & - & - \\
\hline $\begin{array}{l}\text { Calls to family planning } \\
\text { clinic§ }\end{array}$ & $0(0)$ & $0(0)$ & $0(0.33)$ & 0.11 & - & - & - \\
\hline \multicolumn{8}{|c|}{$\begin{array}{l}\text { RS=repeat smear, IC=informed choice, STAI=state-trait anxiety inventory, CSQ=cervical screening questionnaire, PEAPS-Q=psychosocial eff } \\
\text { abnormal Pap smears questionnaire. } \\
\mathrm{F} \text { test (ANOVA with unbalanced design) used for all continuous variables. } \\
\text { *Pairwise comparisons were made only if P<0.1. } \\
\text { †Higher scores represent poorer psychological wellbeing. } \\
\mp \mathrm{X}^{2} \text { test (independent proportions) used for categorical variables. } \\
\S \text { Median (interquartile range) number of visits or calls per questionnaire and non-parametric Kruskal-Wallis and Wilcoxon tests reported. }\end{array}$} \\
\hline
\end{tabular}

and assessed psychological outcomes over 12 months. The authors found that there were no differences in outcomes between women offered a choice and those who were not. ${ }^{40}$ However, the details of how women made their choice and what information they were given are unclear. Participants were informed in a discussion with their clinician and appeared to make their choice immediately. There was no attempt to give women standardised evidence based information on the advantages and disadvantages of each management. In our study, women were given an evidence based decision aid that clearly described the advantages and disadvantages of each option. Our previous analyses of women in the informed choice arm showed that $78 \%$ of women were knowledgeable (scored over $50 \%$ on the knowledge scale) and $68 \%$ of women made an informed choice. ${ }^{14}$ This finding suggests that most women were aware of the options and were able to make an informed choice.

Although our findings are informative, there are limitations to the study. The area based method used to analyse the psychological outcomes over a year of follow-up involved both the interpolation and extrapolation of data. We tried to minimise extrapolation where possible and carefully excluded participants where substantial extrapolation was required. Sensitivity analysis, adopting both less stringent exclusion criteria, and including all data for analysis, as well as analyses by three periods of follow-up time encompassing the three key events of the HPV triage, the smear triage and the post triage follow-up showed similar results and interpretation, indicating that the analysis method chosen is robust. The area based method is necessary to capture the inherent time differences between the two triage managements. Although more complex than selecting arbitrary points in time for comparison, it allows us to compare the entire period of management for both arms (including the six month waiting time in the smear triage arm) and make maximum use of the longitudinal data.

As with all randomised trials, there are questions about generalisability. Our study included participants in the national cervical screening programme from across Australia with a range of educational 
Table 5 |Knowledge scores measured at two week follow-up

\begin{tabular}{|c|c|c|c|c|c|c|c|}
\hline & \multicolumn{3}{|c|}{ Trial arm mean scores } & \multirow[b]{2}{*}{ Overall $\mathrm{P}$ value } & \multicolumn{3}{|c|}{ P value for pairwise comparisons* } \\
\hline & HPV test & IC & RS & & HPV $v$ RS & HPV $v$ IC & IC $v$ RS \\
\hline Knowledge score & 7.3 & 8.1 & 7.2 & 0.01 & - & $<0.01$ & 0.02 \\
\hline $\begin{array}{l}\text { Cervical smear } \\
\text { knowledge }\end{array}$ & 4.2 & 4.7 & 3.7 & $<0.001$ & 0.06 & 0.01 & $<0.001$ \\
\hline $\begin{array}{l}\text { HPV } \\
\text { knowledge }\end{array}$ & 3.1 & 3.2 & 2.2 & $<0.001$ & $<0.001$ & - & $<0.001$ \\
\hline
\end{tabular}

RS=repeat smear, IC=informed choice. $F$ test (ANOVA with unbalanced design) used for all continuous variables.

*Pairwise comparisons were made if $\mathrm{P}<0.1$.

backgrounds. Women participating in the study might possibly have been more interested in HPV testing and the opportunity to choose management. However, we note that preference for HPV testing in the informed choice arm was $65 \%$, whereas in a nationally representative sample of Australian women we surveyed, 85\% preferred HPV triage testing (data not shown). We also highlight that the offer of choice might be best suited to those women who want a choice in their health care, which would make our sample appropriate.

All women in our study had conventional cytology and therefore had to re-attend the family planning clinic for another swab to be taken for their HPV test. For women who undergo liquid based cytology, a further test is not required, since the HPV triage procedure can be performed on the original cytology specimen. Our findings showed a clear overall preference for HPV triage among women in the informed choice group $(65 \%$ v 35\%). The use of liquid based cytology and reflex testing would probably further increase preferences for HPV test among women than we have recorded in the current study. Similarly, in the UK HPV Sentinel Sites Implementation Project, women testing HPV negative are returned to routine screening, rather than a 12 month smear test, as used in the study and the ALTS protocol. ${ }^{18}$ This change would be further likely to favour management by HPV triage and adds further support to this triage strategy.

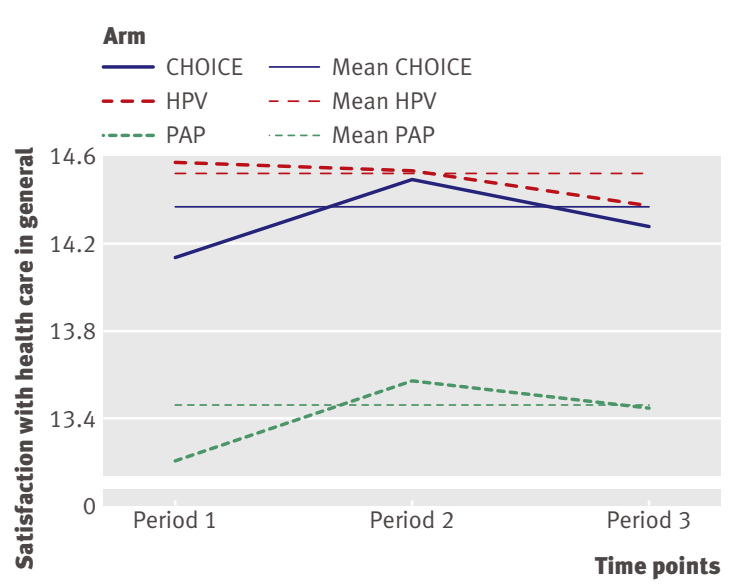

Fig 4: | Mean satisfaction with health care in general for period 1 (90-160 days), period 2 (161-320 days) and period 3 (321-365 days) and mean satisfaction with health care in general for the entire study period

\section{CONCLUSION}

Although psychosocial outcomes of management by HPV testing for women with a borderline smear are initially worse than with conventional management, over 12 months, the outcomes appear to be better. The difference between offering women a choice of management and allocating them directly to HPV triage appears small, with the possible advantage of reduced intrusive thoughts and perhaps worry in the choice arm. Overall, women were more satisfied with HPV triage or a choice, and outcomes were worse for women allocated to smear testing. The findings suggest that there are no lasting psychosocial disadvantages to HPV triage, and in view of other potential advantages, the findings support the move towards HPV triage in the UK for women with borderline smear results. However, we note our study did not include women with mild dyskaryosis who are currently included in NHS Cervical Screening Programme HPV Sentinel Sites Implementation Project. We also highlight that women in the HPV arm were well informed about HPV infection which might have mitigated some of the negative psychosocial sequelae observed in previous studies. Care should be taken to ensure clear and accessible HPV information is provided to women alongside HPV testing.

We thank Elizabeth Davey for her advice and assistance with clinical aspects of the IMAP trial; FPA Health (NSW), Illawarra Women's Health

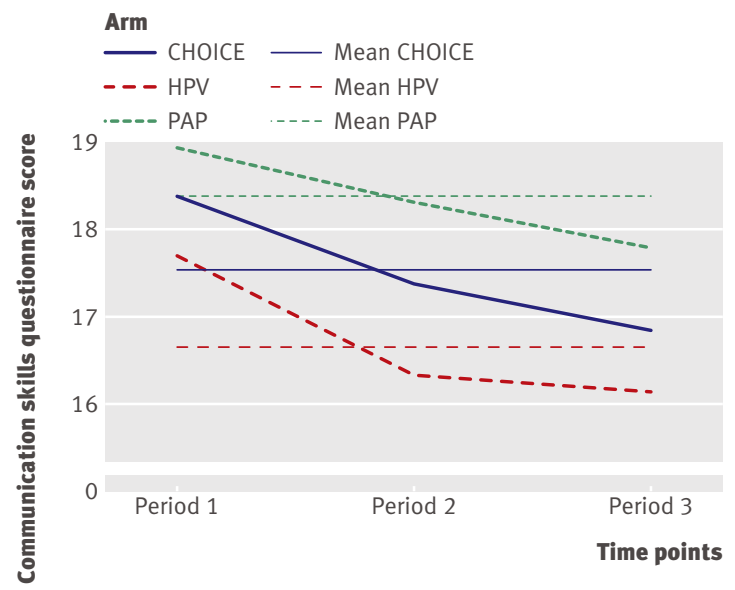

Fig 5: | Mean cervical screening questionnaire (CSO) distress scores for the period 1 (90-160 days), period 2 (161-320 days) and period 3 (321-365 days) and mean CSQ distress scores for the entire study period 


\section{WHAT IS ALREADY KNOWN ON THIS TOPIC}

HPV testing for triage of women with borderline cervical abnormalities is available in the US and Europe and is soon to be introduced into the cervical screening programme in England and Wales

HPV triage has advantages but also potential downsides with respect to women's quality of life and psychosocial wellbeing, but these outcomes, and the option of offering women informed choice of management, have not been adequately assessed

\section{WHAT THIS STUDY ADDS}

HPV triage is better than conventional management by repeat cervical smear testing for women's psychosocial wellbeing, with reduced distress about the abnormal smear result over a year

The benefit of giving women an informed choice of either HPV testing or repeat smear testing supported by a decision aid is uncertain

Offering management by HPV testing appears justified to optimise psychosocial outcomes for women with borderline cervical abnormalities
Centre (NSW), Family Planning Queensland (FPQ), Family Planning ACT, SHINE (South Australia), and Family Planning WA (FPWA) for their assistance with the recruitment and testing of IMAP study participants; Julie Cayley, Ruth Terwijn, Julie Adrian, Shane Jasiak, Ann Hutchings, Pauline Lee, Wendy Jarrett, Marilyn Grey, Lynn Wray, Caroline Harvey, Sally Page, Jacqui McLelland, Sonya Melgram, Jody Monroe, Judith Collision, Angela Cooney, Katrina Allen, Sue Plume, Sue Opie, Robin Pretty, Edith Melgarejo, Mary Poole, Elizabeth Bowen, Libby Knight, Catherine Turnbull, Jane Newman and Angela Triggs, and staff at Symbion Laverty Pathology.

Contributors: $\mathrm{KM}$ and $\mathrm{LI}$ conceived the study. $\mathrm{KM}, \mathrm{LI}, \mathrm{PM}$ and $\mathrm{AB}$ all contributed to the study design. KM led the research team, data collection, and writing of the manuscript. ML and JC assisted with the all aspects of running the study and coordination the data collection. SFC developed the study database and assisted with the initial analysis. RT carried out the statistical analysis with advice from PM and LI. EW advised on clinical aspects of the study. All authors contributed to the interpretation of the analysis and the writing of the manuscript. KM, LI, RT, and PM are guarantors.

Funding: This work was supported by an Australian National Health and Medical Research Council (NHMRC) Grant 402764 to the Screening and Test Evaluation Program. KM is supported by a NHMRC Career Development Award 402836. The NHMRC has played no role in the writing of this paper.

Competing interests: KM has received a speaker's fee from CSL (producers of the HPV quadrivalent vaccine Gardasil) and a consultancy fee from GlaxoSmithKline (producers of the bivalent HPV vaccine, Cevarix). EW has received honoraria and research funding from GSK and CSL for her research in the area of HPV vaccination. All other authors have no conflict of interest

Ethical approval: Ethical approval was granted by the University of Sydney human research ethics committee and all ethics committees governing the participating family planning clinics.

1 TOMBOLA. Options for managing low grade cenvical abnormalities detected at screening: cost effectiveness study. $B M$ J 2009;339:b2549.

2 Franco EL. Managing low grade and borderline cervical abnormalities. BMJ 2009;339:b3014.

3 National Health Service Information Centre for health and social care. Cervical Screening Programme, England 2007-08, 2008. www.ic. nhs.uk/statistics-and-data-collections/screening/cervicalscreening/cervical-screening-programme-england-2008-09.

4 Moss S, Gray A, Legood R, Vessey M, Patnick J, Kitchener H. Effect of testing for human papillomavirus as a triage during screening for cervical cancer: observational before and after study. $B M J$ 2006;332:83-5.

5 Maissi E, Marteau TM, Hankins M, Moss S, Legood R, Gray A. Psychological impact of human papillomavirus testing in women with borderline or mildly dyskaryotic cervical smear test results: cross sectional questionnaire study. BMJ 2004;328:1293-8.
6 Marteau TM, Walker P, Giles J, Smail M. Anxieties in women undergoing colposcopy. Br J Obstet Gynaecol 1990;97:859-61.

7 McCaffery K, Waller J, Forrest S, Cadman L, Szarewski A, Wardle J. Testing positive for human papillomavirus in routine cervical screening: examination of psychosocial impact. BJOG 2004;111:1437-43.

8 McCaffery KJ, Waller J, Nazroo JN, Wardle J. Social and psychological impact of HPV testing in cervical screening: a qualitative study. Sex Transm Infect 2006;82:69-74.

9 Irwig L, McCaffery K, Salkeld G, Bossuyt P. Informed choice for screening: implications for evaluation. BMJ 2006;332:1148-50.

10 Raffle AE. Informed participation in screening is essential. $B M$ J 1997;314:1762-3.

11 Entwistle VA, Carter SM, Trevena L, Flitcroft K, Irwig L, McCaffery K, et al. Communicating about screening. BMJ 2008;337:a1591.

12 O'Connor AM, Stacey D, Entwistle V, Llewellyn-Thomas H, Rovner D, Holmes-Rovner M, et al. Decision aids for people facing health treatment or screening decisions. Cochrane Database Syst Rev 2003;(2):CD001431.

13 McCaffery K, Irwig L, Bossuyt P. Patient decision AIDS to support clinical decision making: evaluating the decision or the outcomes of the decision. Med Decis Making 2007;27:619-25.

14 McCaffery KJ, Irwig L, Chan SF, Macaskill P, Barratt A, Lewicka M, et al. HPV testing versus repeat Pap testing for the management of a mino abnormal Pap smear: evaluation of a decision aid to support informed choice. Patient Educ Couns 2008;73:473-9, 81.

15 O'Connor AM, Tugwell P, Wells GA, Elmsie T, Jolly E, Bunn H, et al. The Ottawa Decision Support Framework (DSF) Guiding the development of decision aids for patients and practitioners considering health care interventions. 1998

16 ASCUS-LSIL Triage Study (ALTS Group). Results of a randomized tria on the management of cytology interpretations of atypical squamous cells of undetermined significance. Am J Obstet Gynecol 2003;188:1383-92.

17 ASCUS-LSIL Triage Study (ALTS Group). A randomized trial on the management of low-grade squamous intraepithelial lesion cytology interpretations. Am J Obstet Gynecol 2003;188:1393-400.

18 Schiffman M, Adrianza ME. ASCUS-LSIL Triage Study. Design, methods and characteristics of trial participants. Acta Cytol 2000;44:726-42.

19 National Health and Medical Research Council. Screening to prevent cervical cancer: guidelines for the management of women with screen detected abnormalities. In: Service AGP, ed. Canberra: Commonwealth Department of Human Services and Health, 1994.

20 Bossuyt P, McCaffery K. Additional Pathways and Outcomes in Evaluations of Testing. Medical Decision Making 2009;29:E30-8.

21 Ware J, Kosinski M, Keller S. SF-36 health survey manual and interpretation guide. 2nd ed. The Health Institute, New England Medical Centre, 1994.

22 Sutton S, Bickler G, Sancho-Aldridge I, Saidi G. Prospective study of predictors of attendance for breast screening in inner London. . Epidemiol Community Health 1994;48:65-73.

23 Wardle J, Pernet A, Stephens D. Psychological consequences of positive results in cervical cancer screening. Psychol Health 1995;10:185-94.

24 Horowitz M, Wilner, N, Alvarez, MA. Impact of Event Scale: A measure of subjective stress. Psychosom Med 1979;41:209-18.

25 Ware J, Sydner MK., Wright, WR. Development and validation of scales to measure patient satisfaction with healthcare services. University of Illinois, 1976.

26 Marteau TM, Bekker H. The development of a six-item short-form of the state scale of the Spielberger State-Trait Anxiety Inventory (STAI). BrJ Clin Psychol 1992;31(Pt 3):301-6.

27 Bennetts A, Irwig L, Oldenburg B, Simpson JM, Mock P, Boyes A, et al PEAPS-Q: a questionnaire to measure the psychosocial effects of having an abnormal Pap smear. J Clin Epidemiol 1995;48:1235-43.

28 Rosenberg M. Society and the adolescent self-image. Princeton University Press, 1965.

29 Campion MJ, Brown JR, McCance DJ, Atia W, Edwards R, Cuzick J, et al. Psychosexual trauma of an abnormal cervical smear. Br J Obstet Gynaecol 1988;95:175-81.

30 Satterthwaite FW. An approximate distribution of estimates of variance components. Biometrics Bull 1946;2:110-14.

31 Contopoulos-loannidis DG, Karvouni A, Kouri I, loannidis JP. Reporting and interpretation of SF-36 outcomes in randomised trials: systematic review. BMJ 2009;338:a3006.

32 Revicki D, Hays RD, Cella D, Sloan J. Recommended methods for determining responsiveness and minimally important differences for patient-reported outcomes. J Clin Epidemiol 2008;61:102-9. 
33 Australian Bureau of Statistics. National Health Survey SF 36 population Norms. Australia. Canberra: ABS Catalogue Number 4399.0, 1997.

34 Sanson-Fisher R, Perkins, JJ. Adaption and validation of the SF-36 health survey for use in Australia. J Clin Epidemiol 1998;51:961-7.

35 Maissi E, Marteau TM, Hankins M, Moss S, Legood R, Gray A. The psychological impact of human papillomavirus testing in women with borderline or mildly dyskaryotic cervical smear test results: 6month follow-up. Br J Cancer 2005;92:990-4.

36 Feise RJ. Do multiple outcome measures require p-value adjustment? BMC Med Res Methodol 2002;2:8.

37 Kitchener HC, Fletcher I, Roberts C, Wheeler P, Almonte M, Maguire P. The psychosocial impact of human papillomavirus testing in primary cervical screening-a study within a randomized trial. Int J Gynecol Cancer 2008;18:743-8.

38 Waller J, McCaffery K, Forrest S, Szarewski A, Cadman L, Wardle J. Awareness of human papillomavirus among women attending a well woman clinic. Sex Transm Infect 2003;79:320-2.

39 Waller J, McCaffery K, Nazroo J, Wardle J. Making sense of information about HPV in cervical screening: a qualitative study. Br J Cancer 2005;92:265-70.

40 Kitchener HC, Burns S, Nelson L, Myers AJ, Fletcher I, Desai M, et al. A randomised controlled trial of cytological surveillance versus patient choice between surveillance and colposcopy in managing mildly abnormal cenical smears. Br J Obstet Gynaecol 2004;111:63-70.

Accepted: 9 September 2009 